\title{
Transplantation of Olfactory Mucosa Minimizes Axonal Branching and Promotes the Recovery of Vibrissae Motor Performance after Facial Nerve Repair in Rats
}

\author{
Orlando Guntinas-Lichius, ${ }^{1}$ Konstantin Wewetzer, ${ }^{3}$ Toma L. Tomov, ${ }^{2}$ Natalie Azzolin, ${ }^{2}$ Shohreh Kazemi, ${ }^{2}$ \\ Michael Streppel, ${ }^{3}$ Wolfrum F. Neiss, ${ }^{2}$ and Doychin N. Angelov ${ }^{2}$ \\ Departments of ${ }^{1}$ Oto-Rhino-Laryngology and ${ }^{2}$ Anatomy, University of Cologne, 50931 Cologne, Germany, and \\ 3 Department of Neuroanatomy, Hannover Medical School, 30625 Hannover, Germany
}

The occurrence of abnormally associated movements is inevitable after facial nerve transection. The reason for this postparalytic syndrome is poor guidance of regrowing axons, whereby a given muscle group is reinnervated by misrouted axonal branches. Olfactory ensheathing glia have been shown to reduce axonal sprouting and stimulate axonal regeneration after transplantation into the spinal cord. In the present study, we asked whether transplantation of olfactory mucosa (OM) would also reduce sprouting of a damaged peripheral pure motor nerve. The adult facial nerve was transected, and the effect of the OM placed at the lesion site was analyzed with regard to the accuracy of target reinnervation, axonal sprouting of motoneurons, and vibrissal motor performance. Accuracy of target reinnervation and axonal sprouting were studied using preoperative/postoperative labeling and triple retrograde labeling of facial motoneurons, respectively. The vibrissal motor performance was monitored using a video-based motion analysis. We show here that implantation of OM, compared with simple facial-facial anastomosis, (1) improved the protraction, amplitude, angular velocity, and acceleration of vibrissal movements up to $80 \%$ of the control values, (2) reduced the percentage of branching motoneurons from 76 to $39 \%$, and (3) improved the accuracy of reinnervation from 22 to $49 \%$. Moreover, we present evidence, that transplanted OM but not buccal mucous membrane induced a sustained upregulation of trophic factors at the lesion site. It is concluded that transplantation of $\mathrm{OM}$ to the transected facial nerve significantly improves nerve regeneration.

Key words: regeneration; olfactory ensheathing glia; axonal pathfinding; collateral sprouting; retrograde labeling; whisking behavior
The peripheral nervous system is generally characterized by its ability to achieve functional recovery after peripheral nerve injury. However, complete recovery of function in the clinical practice is only rarely observed. The occurrence of abnormally associated movements and altered reflexes is practically inevitable, especially after surgical repair of the facial nerve (Kimura et al., 1975; Anonsen et al., 1986; Baker et al., 1994).

The main reason for this "post-paralytic syndrome" is the "misdirected" or "aberrant" reinnervation of muscles (Montserrat and Benito, 1988), which has two components. First, because of malfunctioning axonal guidance, a muscle becomes reinnervated by a "foreign" axon, which has been misrouted along the "wrong" fascicle (Esslen, 1960; Aldskogius and Thomander, 1986; Brushart and Seiler 1987), and second, because of the presence of supernumerary branches from all transected axons (Shawe, 1954; Morris et al., 1972), a muscle is simultaneously reinnervated by several motoneurons (Ito and Kudo, 1994), a state known as

\footnotetext{
Received March 20, 2002; revised May 13, 2002; accepted June 6, 2002.

This study was supported by the Deutsche Forschungsgemeinschaft (AN-331/2-1), the Köln Fortune Program of the Faculty of Medicine, University of Cologne, the Jean-Uhrmacher-Foundation, and the Megapharm GmbH, Germany. The skillful technical assistance of I. Rohrmann and D. Felder and the fine photographical work of I. Koch and the precise drawings of J. Ribbers are highly appreciated. We thank N. v. Dornick for editorial help.

Correspondence should be addressed to Dr. Doychin N. Angelov, Anatomical Institute University of Cologne, Joseph-Stelzmann-Strasse 9, 50931 Cologne, Germany. E-mail: angelov.anatomie@uni-koeln.de.

Copyright (C) 2002 Society for Neuroscience $\quad 0270-6474 / 02 / 227121-11 \$ 15.00 / 0$
}

“polyneuronal innervation” (Brown et al., 1981; Rich and Lichtman, 1989) or "hyperinnervation" (Angelov et al., 1993, 1996).

Attempts to act on the first component of aberrant reinnervation, achieving a "fascicular" or "specificity" (Mackinnon et al., 1986; Evans et al., 1991) have failed so far. Although claimed to be transient (Hennig and Dietrichs, 1994), the aberrant innervation may persist for extended periods (Mackinnon et al., 1991; Madison et al., 1999), with deleterious effects on synchronized function. Thus, the post-lesional axonal branching, considered to represent the search of axons for local guidance cues (AlMajed et al., 2000), may be the reason for the failure of axons to reinnervate solely their original domain (Fu and Gordon, 1997; Angelov et al., 1999).

Observations suggested that implantations of olfactory ensheathing cells (OECs) minimized axonal sprouting in the spinal cord. We therefore studied the effects of purified cultured neonatal OECs transplanted into the transected facial nerve and were surprised to find that implantation of OECs dramatically increased sprouting of axotomized facial motoneurons (Guntinas-Lichius et al., 2001). This effect may be explained by high levels of trophic factors provided in situ by the transplanted cells (Bunge, 1993; Gallo and Letourneau, 1998; Davies, 2000; Mackay-Sim and Chuah, 2000; Raisman, 2001). Recent evidence indicates that the dissociation and prolonged cultivation of OECs results in upregulation of trophic factors involved in axonal sprouting, e.g., the ciliary neurotrophic factor (CNTF) and its $\alpha$ receptor subunit (Lee et al., 1997; Wewetzer et al., 2001). To prevent excessive trophic factor supply by cultured OECs, we 
chose to use instead intact autologous olfactory mucosa (OM) for transplantation. OM has been successfully applied recently to the experimentally lesioned spinal cord (Lu et al., 2001, 2002).

Comparing (1) the degree of axonal branching, (2) the accuracy of muscle target reinnervation, and (3) the motor performance of the vibrissal hairs between rats with facial nerve suture only (FFA) and rats with FFA plus small pieces of OM transplanted at the suture site, we found that the addition of OM significantly improved the quality of target innervation and recovery of function.

\section{MATERIALS AND METHODS}

\section{Materials}

Fluoro-Gold (FG) was purchased from Fluorochrome Inc. (Denver, $\mathrm{CO}$ ), Fast Blue (FB) was from EMS-Chemie GmbH (Gro $\beta$-Umstadt, Germany), and 1,1'-dioctadecyl-3,3,3',3'-tetramethylindocarbocyanin perchlorat (DiI) was from Molecular Probes (Leiden, The Netherlands; cat. no. D-282).

\section{Animals and surgery}

Forty female and 6 male inbred Lewis rats (175-200 gm; strain LEW/ SSN; Harlan Winkelmann, Borchen, Germany) were used. Before and after the experiments, rats were kept on standard laboratory food (Ssniff, Soest, Germany) and tap water ad libitum, with an artificial $12 \mathrm{hr}$ light/dark cycle. All surgical procedures were performed under microscopic control after an intraperitoneal injection of ketamin/xylazin as described previously (Dohm et al., 2000; Guntinas-Lichius et al., 2001). All experiments were conducted in accordance with the German Law for Animals' Protection and approved by the local animal care committee (Bezirksregierung Köln, Az. 23.203.2-K35,13/95).

Transection and immediate end-to-end suture of the right facial nerve (facial-facial anastomosis) was performed in female rats only. As described previously, the main trunk of the facial nerve was exposed under deep anesthesia and transected close to its emergence from the foramen stylomastoideum, distal to the posterior auricular branch (see Fig. 1A). The proximal stump was then microsurgically reconnected to the distal stump with two 11-0 atraumatic sutures (Ethicon EH 7438G, Ethicon, Norderstedt, Germany).

In half of the female rats, OM, freshly prepared from deeply anesthetized syngeneic male rats, was cut in small pieces after a short rinse in HBSS (Life Technologies Overseas GmbH; cat. no. 24020083) and then gently laid over the sutured epineurium. Male rats were chosen as donors to facilitate a later identification of the transplant in the female hosts. Finally, the wound was closed by three 4-0 skin sutures (Ethicon).

In four other female rats, buccal mucous membrane (BMM) obtained from the cheeks of deeply anesthetized syngeneic male animals was laid over the sutured epineurium. These control rats were used to prove whether the improved regeneration was really caused by OM and not by the mechanical effect(s) of any transplanted tissue.

\section{Estimation of post-operative axonal branching}

Triple retrograde labeling was performed as reported previously (Dohm et al., 2000; Guntinas-Lichius et al., 2001). Briefly, the zygomatic, buccal, and marginal mandibular ramus of intact animals (six rats), of animals that received an OM transplant (six rats), and of animals that underwent FFA-only (six rats) were transected, and tracer crystals (DiI, FG, FB) were applied (see Fig. $1 B$ ). Tracing was done 2 months after the operation. Ten days after the post-operative bilateral labeling, rats were transcardially perfused $(0.9 \% \mathrm{NaCl}$ in distilled water) followed by fixation with $4 \%$ paraformaldehyde $(0.1 \mathrm{M}$ phosphate buffer, $\mathrm{pH} 7.4)$ under deep anesthesia. Brainstems were cut coronally $(50 \mu \mathrm{m})$ using a vibratome.

Sections were evaluated using an epifluorescence microscope (Zeiss Axioskop 50) a custom-made bandpass-filter set for Fast Blue, and a HQ-Schmalband-filter set for Fluoro-Gold. The use of an additional filter set (filter set 15, Carl Zeiss; excitation BP 546/12, emission LP 590) revealed the red fluorescence of those motoneurons retrogradely labeled by DiI. The fluorescence cross-talk between the tracers was restricted with this filter combination ad maximum (Dohm et al., 2000; GuntinasLichius et al., 2001).

Unfortunately, some FB-labeled motoneurons could be seen even through the HQ-Schmalband-filter set. This imposed serious difficulties when a differentiation between single-labeled (FG or FB) and doublelabeled $(\mathrm{FG}+\mathrm{FB})$ motoneurons had to be made. Therefore, in the present study we counted as double labeled neurons only those containing DiI + FG or DiI + FB but did not evaluate those labeled by FG + FB.

Image analysis was done using a CCD video camera (Optronics Engineering DEI-470) combined with the image analyzing software Optimas 6.5. (see above). For a detailed description of the procedure, see Dohm et al. (2000). Using the fractionator principle (Gundersen, 1986), all retrogradely labeled motoneurons with a visible cell nucleus were counted in every third section through the facial nucleus on the operated and unoperated sides (Guntinas-Lichius et al., 1993). All counts were performed by two observers who were blind to the surgical procedure used on the rats.

\section{Determining the accuracy of target reinnervation}

Intramuscular injection of tracer (FG) was used to reveal the distribution of the original motoneuron pool. Under deep anesthesia, FG dissolved in distilled water $(1 \mathrm{mg} / 100 \mu \mathrm{l})$ containing $2 \%$ dimethyl sulfoxide (DMSO) was injected into each whisker pad of 18 intact rats. Ten days later, six animals underwent FFA-only, and six underwent FFA + OM. The last six rats remained unoperated and received the second label (FB) 2 months later. Two months after FFA-only or FFA + OM, all rats (including the six intact animals) received bilateral injections of FB (1\%) into the whisker pad musculature, at the site of the primary FG injection (Popratiloff et al., 2001, their Fig. 1). Ten days after the post-operative bilateral labeling, all 18 rats were fixed ( $4 \%$ paraformaldehyde $/ 0.1 \mathrm{M}$ phosphate buffer, $\mathrm{pH}$ 7.4) under deep anesthesia, and the brainstems were cut coronally $(50 \mu \mathrm{m})$.

Qualitative fluorescence microscopy was performed with a UVexcitation filter (Carl Zeiss; Filter Set 01, excitation BP 365/12, emission LP 397), which allows recognition of both FG- and FB-labeled neurons. The CCD video camera system, together with the image analyzing software (see above), was used to create separate images of the FG and FB retrogradely labeled facial motoneurons. Custom-made filter sets for FG and FB [(AHF Analysentechnik, Tübingen, Germany) FG-filter: HQ-Schmalband-filter set (no. F36-050; excitation D 369/40; beamsplitter 400DCLP; Barrierfilter HQ 635/30); FB-filter: Bandpass-filter set (no. F31-000; excitation D 436/10; beamsplitter 450 DCLP; Barrierfilter D470/40)] were used. The generated masks of FG-labeled cells were superimposed over the FB image for the unlesioned as well as for the lesioned facial nucleus (Popratiloff et al., 2001). In this way, all motoneurons stained by FG and FB and double labeled by FG + FB could be readily identified and counted.

\section{Analysis of vibrissae motor performance}

The key movements of the vibrissae are protraction (see Fig. 1B) and retraction (see Fig. 1C). Because all vibrissal piloerector muscles are innervated by the buccal branch (Dörfl, 1985), the whiskers acquire caudal orientation and remain motionless after transection of the facial nerve. Two large vibrissae of the $\mathrm{C}$ row on each side of the face were used for biometric analysis, as described previously (Guntinas-Lichius et al., 2001). Under light anesthesia, all other vibrissae were clipped using small fine scissors, and the animals were inserted into a rodent restrainer (Hugo Sachs Electronik-Harvard Apparatus GmbH, AH 52-0292, 79232 March-Hugstetten, Germany) for $30 \mathrm{~min}$ to pacify them. Using a digital camcorder (Panasonic NV DX-110 EG), animals were videotaped for 3-5 min during active exploration. After calibration, video images of whisking behavior were sampled at $50 \mathrm{~Hz}$ (50 fields per second); the video camera shutter was open for $4 \mathrm{msec}$. Images were recorded on AY-DVM 60 EK mini-cassettes. Captured video sequences were reviewed, and $1.5 \mathrm{sec}$ sequence fragments from each animal were selected for analysis of whisking biometrics. Thereby the stable position of the animal's head, the frequency of whisking, and the degree of vibrissae protraction were considered as selection criteria.

The tip of the rat's nose and the inner angles of both eyes were defined as reference points. Each vibrissa in the spatial model was represented by two points: its base and a point on the shaft $0.5 \mathrm{~cm}$ away from the base. Using this model, the following parameters were evaluated: (1) protraction (i.e., the forward movement of the vibrissae) measured by the rostrally opened angle (in degrees) between the midsagittal plane and the hair shaft (accordingly, maximal protractions were represented by rather low angle values); (2) the whisking frequency as cycles of protraction and retraction (passive backward movement) per second; (3) the amplitude (the difference between maximal retraction and maximal protraction in degrees); (4) the angular velocity during protraction in degrees per 


\section{Table 1. Numbers of retrogradely labeled facial perikarya, the axons of which project through the zygomatic, buccal, and marginal mandibular} branches in intact rats and in rats that underwent unilateral FFA-only or unilateral FFA + OM

\begin{tabular}{|c|c|c|c|c|c|c|}
\hline Surgery & $\begin{array}{l}\text { Neurons with axons } \\
\text { only in the zygomatic } \\
\text { branch (Dil only) }\end{array}$ & $\begin{array}{l}\text { Neurons with axon } \\
\text { sprouts in the zy- } \\
\text { gomatic and buccal } \\
\text { branches } \\
\text { (Dil + FG) }\end{array}$ & $\begin{array}{l}\text { Neurons with axon } \\
\text { sprouts in the zy- } \\
\text { gomatic and mar- } \\
\text { ginal manibular } \\
\text { branches } \\
\text { (Dil + FB) }\end{array}$ & $\begin{array}{l}\text { Total of branched } \\
\text { and unbranched } \\
\text { neurons projecting } \\
\text { in the zygomatic } \\
\text { nerve (Dil, Dil + } \\
\text { FG Dil + FB) }\end{array}$ & $\begin{array}{l}\text { Neurons with axons } \\
\text { only in the buccal } \\
\text { branch (FG-only) }\end{array}$ & $\begin{array}{l}\text { Neurons with axons } \\
\text { only in the mar- } \\
\text { ginal mandibular } \\
\text { branch (FB-only) }\end{array}$ \\
\hline Intact rats & $301 \pm 25^{* 2,3}(100 \%)$ & $0^{* 2,3}$ & $0 * 2,3$ & $301 \pm 25^{* 2} 100 \%$ & $1345 \pm 115$ & $445 \pm 74^{* 3}$ \\
\hline FFA-only & $116 \pm 15^{* 1,3}(24 \%)$ & $239 \pm 42 * 1,350 \%$ & $123 \pm 13^{* 1,3} 26 \%$ & $482 \pm 50 * 1,3100 \%$ & $1734 \pm 183$ & $315 \pm 62 * 3$ \\
\hline $\mathrm{FFA}+\mathrm{OM}$ & $190 \pm 33^{* 1,2}(61 \%)$ & $71 \pm 34^{* 1,2} 23 \%$ & $40 \pm 22^{* 1,2} 16 \%$ & $312 \pm 88^{* 2} 100 \%$ & $1726 \pm 234$ & $1306 \pm 140 * 1,2$ \\
\hline
\end{tabular}

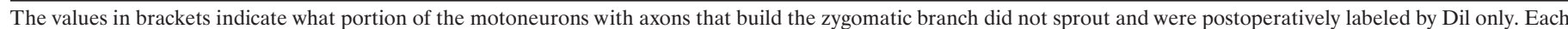

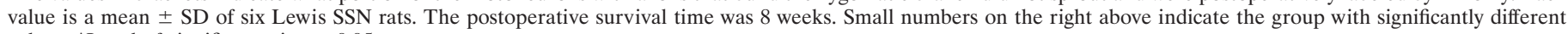
values. ${ }^{*}$ Level of significance is $p<0.05$.

second; and (5) the angular acceleration during protraction in degrees per second squared.

\section{Statistics}

All data were presented as means $\pm \mathrm{SD}$. A one-way ANOVA and a post hoc $t$ test for unpaired data with Bonferroni-Holm correction were applied to detect differences between the different groups. A $p$ value of $<0.05$ was considered statistically significant.

\section{Morphological analysis of the suture/implantation site}

Detection of the transplanted tissue using a Y chromosome-specific DNA probe. To study the definitive localization of the transplanted OM at the end of the experiments and to verify that the transplanted small pieces of olfactory mucosa had not been rejected or degraded, the distribution of the transplanted cells was studied using in situ hybridization and a Y chromosome-specific DNA probe. The Y chromosome is a stable congenic marker that allows the unbiased identification of male cells grafted into female recipients (Irintchev et al., 1997; O'Leary and Blakemore, 1997). All digoxigenin (DIG)-labeled cRNA probes were generated by in vitro transcription, using PCR-generated templates according to the protocols of An et al. (1997).

Hybridization was performed on free-floating sections $(40 \mu \mathrm{m})$ from the facial nerve at the transplantation site 2 months after suture (Haas et al., 1999). Cryosections proceeded through the following steps. (1) Sections were collected in $2 \times \mathrm{SSC}(1 \times \mathrm{SSC}=0.15 \mathrm{M} \mathrm{NaCl}, 0.015 \mathrm{~m}$ sodium citrate, $\mathrm{pH} 7.0$ ); (2) sections were pretreated in a $1: 2$ mixture of $2 \times$ $\mathrm{SSC} /$ hybridization buffer (50\% formamide, $4 \times \mathrm{SSC}, 50 \mathrm{~mm} \mathrm{NaH} \mathrm{PO}_{4}$, $250 \mu \mathrm{g} / \mathrm{ml}$ heat-denatured salmon sperm DNA, $100 \mu \mathrm{g} / \mathrm{ml}$ tRNA, 5\% dextran sulfate, and 1\% Denhardt's solution) for $15 \mathrm{~min}$; (3) prehybridization of sections in hybridization buffer for $60 \mathrm{~min}$ at $55^{\circ} \mathrm{C}$; (4) probe concentration was $100 \mathrm{ng} / \mathrm{ml}$; hybridization lasted $12 \mathrm{hr}$ at $55^{\circ} \mathrm{C}$; (5) sections were washed in $2 \times$ SSC at room temperature; (6) sections were washed in $2 \times$ SSC plus $50 \%$ formamide; (7) sections were washed in $0.1 \times$ SSC and $50 \%$ formamide; (8) sections were washed in $0.1 \times$ SSC (steps 5-8 were performed at a temperature $10^{\circ} \mathrm{C}$ above the respective hybridization temperatures); (9) immunological detection of DIGlabeled hybrids with anti-DIG-alkaline phosphatase was performed as recommended by the manufacturer (Roche); (10) colorimetric detection was performed using nitroblue tetrazolium and 5-bromo-4-chloro-3-indolylphosphate; (11) development of the color reaction was performed in the dark at room temperature and stopped after $30 \mathrm{~min}$ by transfer into $10 \mathrm{~mm}$ Tris/HCl, pH 8.0, 1 mm EDTA; (12) sections were embedded in Moviol (Hoechst). Hybridized male cells showed a dark purple spot in the nucleus, whereas female cell nuclei were unstained. Specificity controls included the omission of the labeled probe, the omission of the antibody to DIG, and the use of female instead of male tissue as a negative control.

Detection of trophic factors at the suture/implantation site using immunohistochemistry. To monitor the expression of trophic factors at the lesion site at the end of the experiments, longitudinal cryosections (20 $\mu \mathrm{m}$ ) through the facial nerve 2 months after FFA-only, FFA + OM, or FFA + BMM were incubated with (1) mouse monoclonal anti-NGF (1:50; Roche; cat. no. 1087754), (2) mouse monoclonal anti-BDNF (1:1000; R\&D Systems; MAB 248), (3) mouse monoclonal anti-basic FGF (bFGF) (1:50; UBI/Biomol; cat. no. 05-117), (4) goat polyclonal anti-rat CNTF (1:100; R\&D Systems; AB557-NA), (5) mouse monoclo- nal anti-IGF-I (1:50; UBI/Biomol; cat. no. 05-172), (6) mouse monoclonal anti-GDNF (1:500; R\&D Systems; MAB 212), (7) rabbit polyclonal anti-S-100 protein (1:1000; Dako Diagnostika, Hamburg, Germany).

Secondary antibodies (all diluted 1:400) were (1) biotinylated goat antimouse IgG (Fc specific, Sigma, no. B-9904), (2) biotinylated rabbit anti-goat IgG (Dako, no. E0466), and (4) biotinylated goat anti-rabbit IgG (Dako, no. E0432), according to standard protocols (Streppel et al., 2002).

\section{RESULTS}

\section{Transplantation of olfactory mucosa reduces the collateral axonal branching}

Transplantation of OM to the site of FFA significantly $(p<0.05)$ reduced axonal collateral branching, as determined by counting the motoneurons that sent an axon through the zygomatic nerve branch and twin branches in two different nerves (Table 1). After transplantation of OM, $312 \pm 88$ motoneurons sent an axon or an axonal branch through the zygomatic ramus compared with $482 \pm$ 50 after FFA-only and $302 \pm 25$ in the intact animal. OM also significantly $(p<0.05)$ reduced the number of double-labeled motoneurons to $\sim 39 \%$ compared with $76 \%$ after FFA. This was accompanied by a significantly $(p<0.05)$ increased portion of motoneurons $(61 \%)$ that sent a single unbranched axon through the zygomatic ramus (Table 1).

Triple retrograde labeling of motoneurons in the intact animals revealed the myotopic organization of the facial nucleus. No double-labeled perikarya were observed; i.e., under normal physiological conditions, motoneurons do not send twin branches to different nerve rami (see Fig. $2 A$ ). No fluorescent perikarya were ever found in the medial or ventromedial facial subnucleus, the motoneurons of which project through the posterior auricular and cervical branch, respectively; neither nerve was an object of transection and labeling. This is in accordance with our previous studies (Dohm et al., 2000; Guntinas-Lichius et al., 2001).

Transection and suture of the facial nerve completely abolished the myotopic organization (see Fig. $2 B$ ). Furthermore, $\sim 75 \%$ of the motoneurons sending an axon to the zygomatic branch gave rise to a twin branch and got double labeled (see Fig. 2B, Table 1 ). The total number of retrogradely labeled motoneurons in all operated animals was higher than that in the control intact rats.

This post-transectional hyperinnervation of targets (Angelov et al., 1996) was caused by a three- to fourfold increase in the number of motoneurons single labeled by FB (Table 1, last column). The majority of axons that took up the retrograde tracer originated from motoneurons projecting under control conditions to the cervical branch of the facial nerve (Fig. $1 A$ ). Because this branch was not traced in intact animals (Fig. $1 B$ ), the corresponding motoneurons were not visible until the post-transectional 
Figure 1. $A, B$, Schematic drawings of the infratemporal portion of the rat facial nerve. The site of transection and end-to-end suture of the facial nerve trunk, i.e., facial-facial anastomosis $(F F A)$, FFA + buccal mucous membrane, or FFA + olfactory mucosa, is indicated by an arrow. The tracer application sites in the distal parts of the transected zygomatic, buccal, and mandibular nerves are indicated by abbreviations of the three different labels applied, i.e., $D i I, F G$, and $F B$, respectively (B). $C, D$, The developed spatial model allows precise measurement of angles, angular velocity, and angular acceleration on the intact (left) and operated side (right) during protraction $(C)$ and retraction $(D)$ of the vibrissae. Note the significant change in angle between the fronto-occipital $(\mathrm{Fr}$-OCc) sagittal line during protraction and retraction on the intact side. The vibrissae on the operated $(O P)$ side remain spastic.

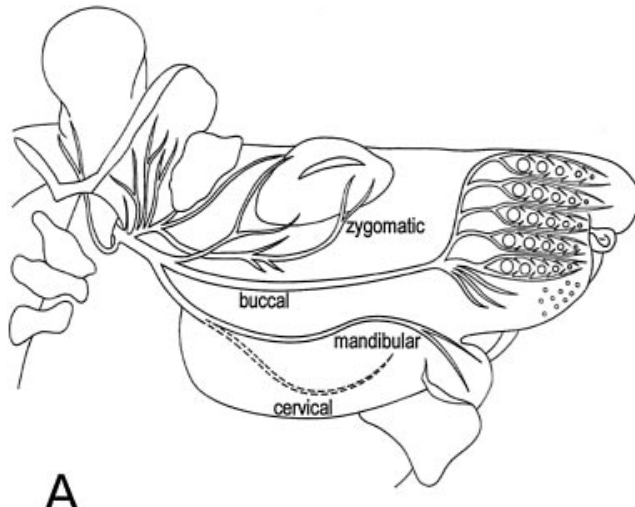

A

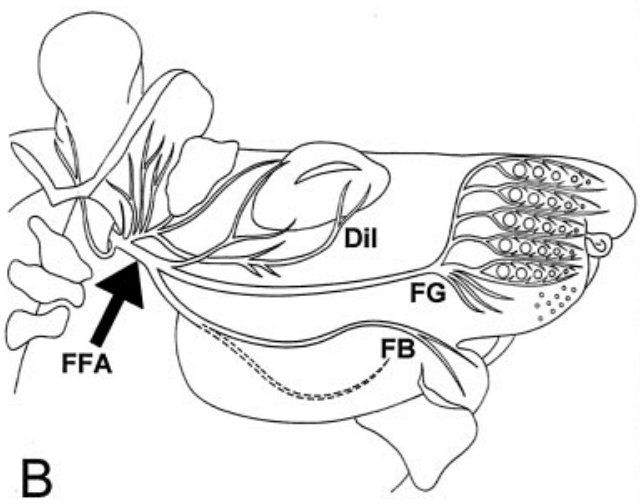

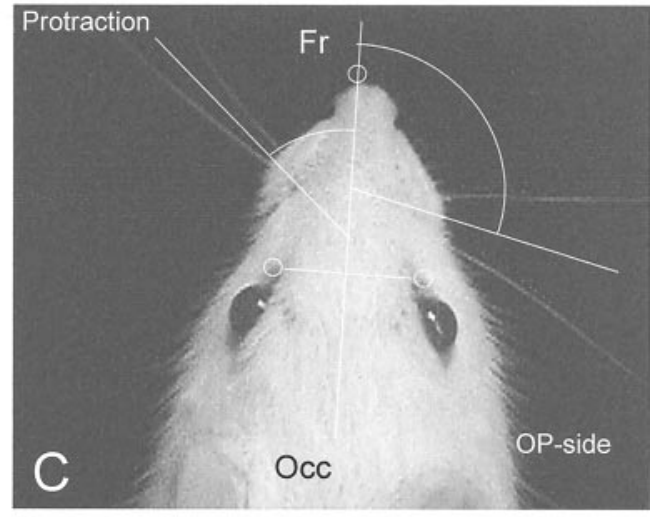

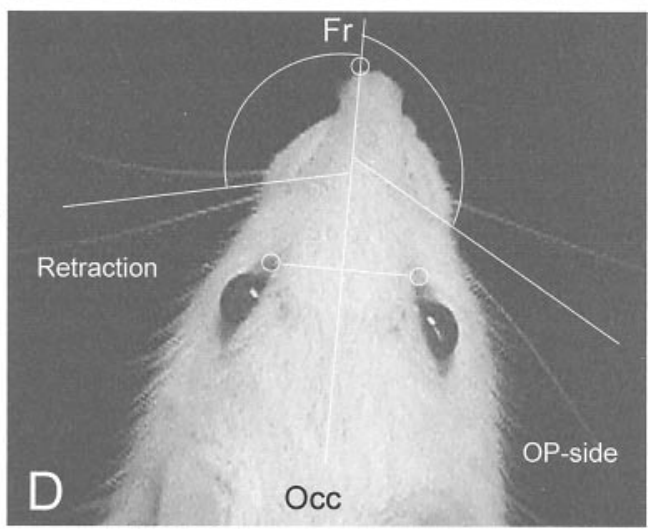

Table 2. Mean number and SD of retrogradely labeled facial perikarya after injection of $100 \mu \mathrm{l} 1 \% \mathrm{FG}$ as a preoperative label and $100 \mu \mathrm{l} 1 \% \mathrm{FB}$ as a postoperative label in intact rats and in rats that underwent unilateral (on the right side) FFA-only or unilateral (on the right side) FFA + OM

\begin{tabular}{|c|c|c|c|c|c|c|}
\hline \multirow[b]{2}{*}{ Surgery } & \multicolumn{3}{|l|}{ Left side } & \multicolumn{3}{|l|}{ Right side } \\
\hline & FG & FB & $\mathrm{FG}+\mathrm{FB}$ & FG & FB & $\mathrm{FG}+\mathrm{FB}$ \\
\hline Intact rats & $1472 \pm 71$ & $1515 \pm 78$ & $1410 \pm 79(96 \%)$ & $1472 \pm 100$ & $1540 \pm 94$ & $1367 \pm 96^{* 2,3}(93 \%)$ \\
\hline FFA-only & $1396 \pm 61$ & $1563 \pm 44$ & $1370 \pm 57(98 \%)$ & $1440 \pm 78$ & $2024 \pm 103$ & $320 \pm 50 * 1(22 \%)$ \\
\hline $\mathrm{FFA}+\mathrm{OM}$ & $1459 \pm 53$ & $1571 \pm 72$ & $1403 \pm 34(96 \%)$ & $1220 \pm 302$ & $1625 \pm 553$ & $597 \pm 283^{* 1}(49 \%)$ \\
\hline
\end{tabular}

The values in brackets indicate what portion of the motoneurons that reinnervated the whisker pad after surgery (FB-labeled) belonged to the original FG-labeled pool. Each

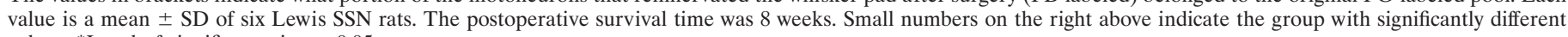
values. * Level of significance is $p<0.05$.

misguidance "lead" their axons into the FB-traced marginal mandibular branch. Although we could detect and report similar changes after insertion of the transected facial nerve in a conduit containing cultured OECs (Guntinas-Lichius et al., 2001) or neutralizing antibodies to trophic factors (Streppel et al., 2002), we still cannot explain why this was not the case in animals that were subjected to FFA-only. Transplantation of OM did not restore the myotopic organization.

Taken together, our data clearly demonstrate that transplantation of OM significantly reduced collateral branching compared with FFA-only but did not completely restore the original innervation pattern as observed in the intact animal. Interestingly, transplantation of $\mathrm{OM}$ significantly increased the number of single-labeled motoneurons projecting in the marginal mandibular branch.

\section{Transplantation of olfactory mucosa does not increase the accuracy of reinnervation}

After transplantation of OM to the suture site, a mean of $1625 \pm$ 553 motoneurons was found to reinnervate the whisker pad compared with $2024 \pm 103$ after FFA and $1540 \pm 94$ in the intact animal (Table 2). However, the reduction of $33 \%$ compared with FFA was statistically not significant. After transplantation of OM, an increased portion of motoneurons was observed that succeeded in reinnervating their original target: $597 \pm 283$ motoneurons correlated to $49 \%$ compared with $320 \pm 50(22 \%)$ after FFA and $1367 \pm 96(93 \%)$ in the intact animal. This increase was also not statistically significant compared with FFA.

Injection of FG into the whisker pad of intact rats was found to label $1472 \pm 71$ facial motoneurons. Two months later, injection of FB as close as possible to the primary injection site labeled $1515 \pm 78$ motoneurons. This demonstrates that there is no difference in the labeling efficiency for FG and FB (Table 2). Moreover, both tracers labeled only motoneurons that were localized in the lateral facial subnucleus, which is in agreement with the myotopic organization of the facial nucleus in intact rats (Fig. $2 C$ ). Control experiments, including the injection of tracers into the intact facial nucleus of the side contralateral to FFA (left side), again revealed no differences in labeling efficiency between 

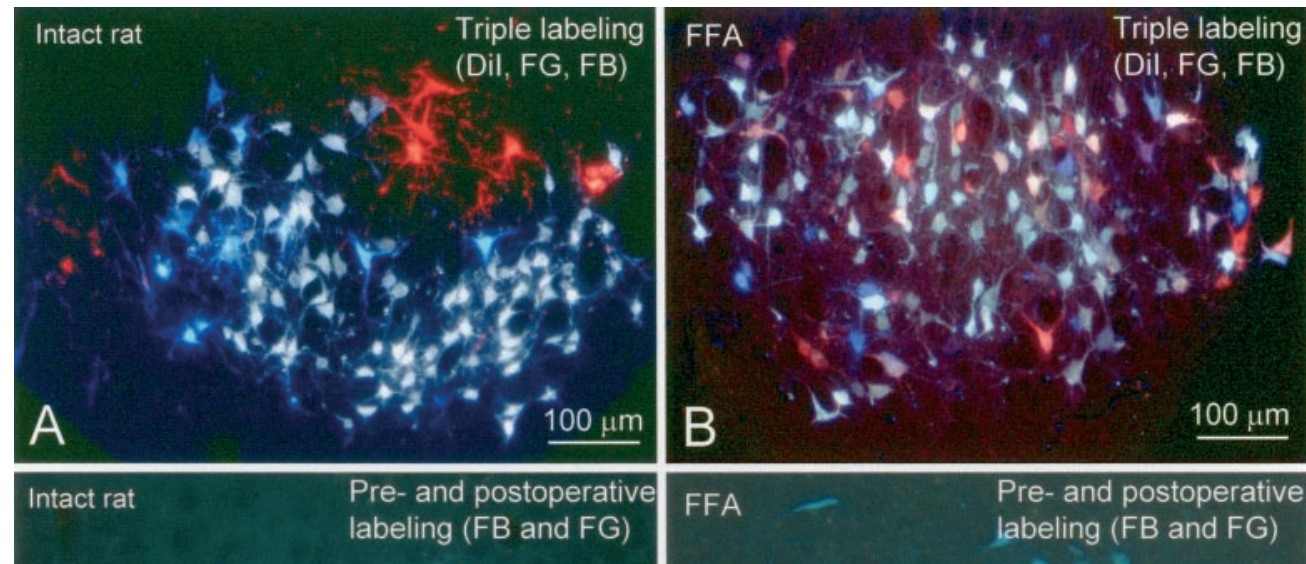

Pre- and postoperative

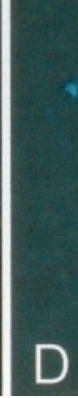

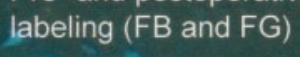

.

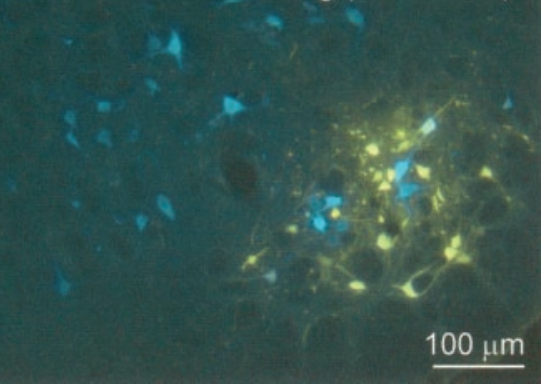

Figure 2. Estimation of postoperative axonal branching $(A, B)$ and accuracy of reinnervation $(C, D)$. $A$, Triple labeling in the facial nucleus after application of crystalline DiI to the zygomatic, FG to the buccal, and FB to the marginal mandibular nerves of an unoperated control rat. Note the myotopic organization of the nucleus. The DiI-labeled motoneurons (red) are localized mostly in the dorsal, FG-labeled (white-yellow) motoneurons are localized mainly in the lateral, and FB-labeled (blue) motoneurons are localized mainly in the intermediate facial subnucleus. $B$, Eight weeks after FFA-only or FFA + OM, the myotopic organization was completely eliminated, and various doublelabeled motoneurons sending branches in different nerve rami were observed. $C$, Unoperated control rat. The preoperative and postoperative neuronal labeling with FG (yellow) and FB (blue) support our counts showing that in the intact facial nucleus, the portion of double-labeled (FG + FB) motoneurons is $>95 \%$ (Table 2). D, Eight weeks after FFA-only or FFA + OM. Although all FG-labeled motoneurons are localized in the lateral facial subnucleus, those labeled with FB are observed dis-

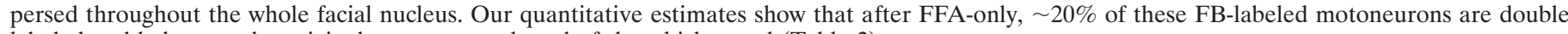
labeled and belong to the original motoneuronal pool of the whisker pad (Table 2).

Table 3. Biometrics of recovering whisking behavior in rats after FFA-only and FFA + OM

\begin{tabular}{|c|c|c|c|c|c|}
\hline $\begin{array}{l}\text { Animal } \\
\text { group }\end{array}$ & $\begin{array}{l}\text { Frequency } \\
\text { (in } \mathrm{Hz})\end{array}$ & $\begin{array}{l}\text { Angle at maximal pro- } \\
\text { traction (in degrees) }\end{array}$ & $\begin{array}{l}\text { Amplitude } \\
\text { (in degrees) }\end{array}$ & $\begin{array}{l}\text { Angular velocity during } \\
\text { protraction (in degrees } \\
\text { per second) }\end{array}$ & $\begin{array}{l}\text { Angular acceleration during } \\
\text { protraction (in degrees per } \\
\text { second squared) }\end{array}$ \\
\hline Intact rats & $5.4 \pm 1.0$ & $44.6 \pm 10.7^{\circ * 2,3}$ & $69.4 \pm 15.3^{\circ * 2,3}$ & $803 \pm 247^{\circ} * 2$ & $25485 \pm 10842^{\circ * 2}$ \\
\hline FFA-only & $5.2 \pm 0.8$ & $84.8 \pm 7.90^{\circ * 1,3}$ & $17.0 \pm 3.80^{\circ * 1,3}$ & $159 \pm 63^{\circ * 1,3}$ & $3308 \pm 1593^{\circ * 1,3}$ \\
\hline $\mathrm{FFA}+\mathrm{OM}$ & $5.7 \pm 0.8$ & $72.0 \pm 11.0^{\circ * 1,2}$ & $44.0 \pm 15.0^{\circ * 1,2}$ & $559 \pm 385^{\circ * 2}$ & $16024 \pm 8508^{\circ * 2}$ \\
\hline
\end{tabular}

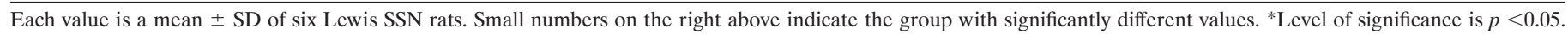

both tracers. The data were comparable to those of the intact animal (see above).

After FFA, no myotopic organization into subnuclei was evident, and the bulk of motoneurons $(\sim 80 \%)$ that were retrogradely labeled by the postoperative tracer FB were scattered throughout the other facial subnuclei (Fig. 2D, Table 2). Because of the post-transectional axonal branching (see above), the number of retrogradely labeled motoneurons in all operated animals was higher than that in the control intact rats.

\section{Transplantation of olfactory mucosa promotes functional recovery of vibrissal motor performance}

The detailed biometric analysis of whisking behavior was performed to test whether the implantation of OM, besides its effect on the axonal collateral formation, also improved motor performance as measured by a functional test. All animals that underwent FFA and transplantation of OM showed a significantly $(p<$ $0.05)$ better recovery of the biometrical parameters than the rats with FFA-only (Table 3 ). This is well demonstrated by the curves representing the angle at maximal protraction and amplitude in Figure 3. Furthermore, the values for the angular velocity and angular acceleration parameters did not differ significantly from those of the intact animals. After surgery and implantation of OM, the vibrissae dropped motionless and "rose" at 10-14 d post-operation (DPO). Initial signs of restoration of rhythmical whisking occurred at 21-28 DPO. An almost complete recovery of function was detected 2 months after surgery.

After FFA-only or FFA + BMM, the vibrissae dropped and acquired a caudal orientation. At 10-14 DPO, the vibrissae rose again to the level of the mouth and acquired a posterior orientation. No signs of restoration of rhythmical whisking were observed.

This is the first demonstration indicating that transplanted tissue exerts beneficial effects on facial nerve regeneration. Recent experiments have shown that neither entubulation in chambers containing agents known to foster neurite regrowth (Dohm et al., 2000) nor implantations of cultured OECs (GuntinasLichius et al., 2001) or Schwann cells (our unpublished observations) are able to promote similar recovery. Because there was no evident functional improvement after transplantation of BMM, we feel confident that this beneficial effect is not caused by a purely mechanical role of any transplanted tissue but solely by the transplanted OM. At the same time, this is why our present results bear particular relevance not only for the basic processes underlying axonal regeneration and pathfinding, which are important for developing novel cell-based therapeutic strategies of nerve injury, but also for the general use of olfactory ensheathing glia in restoration studies. 

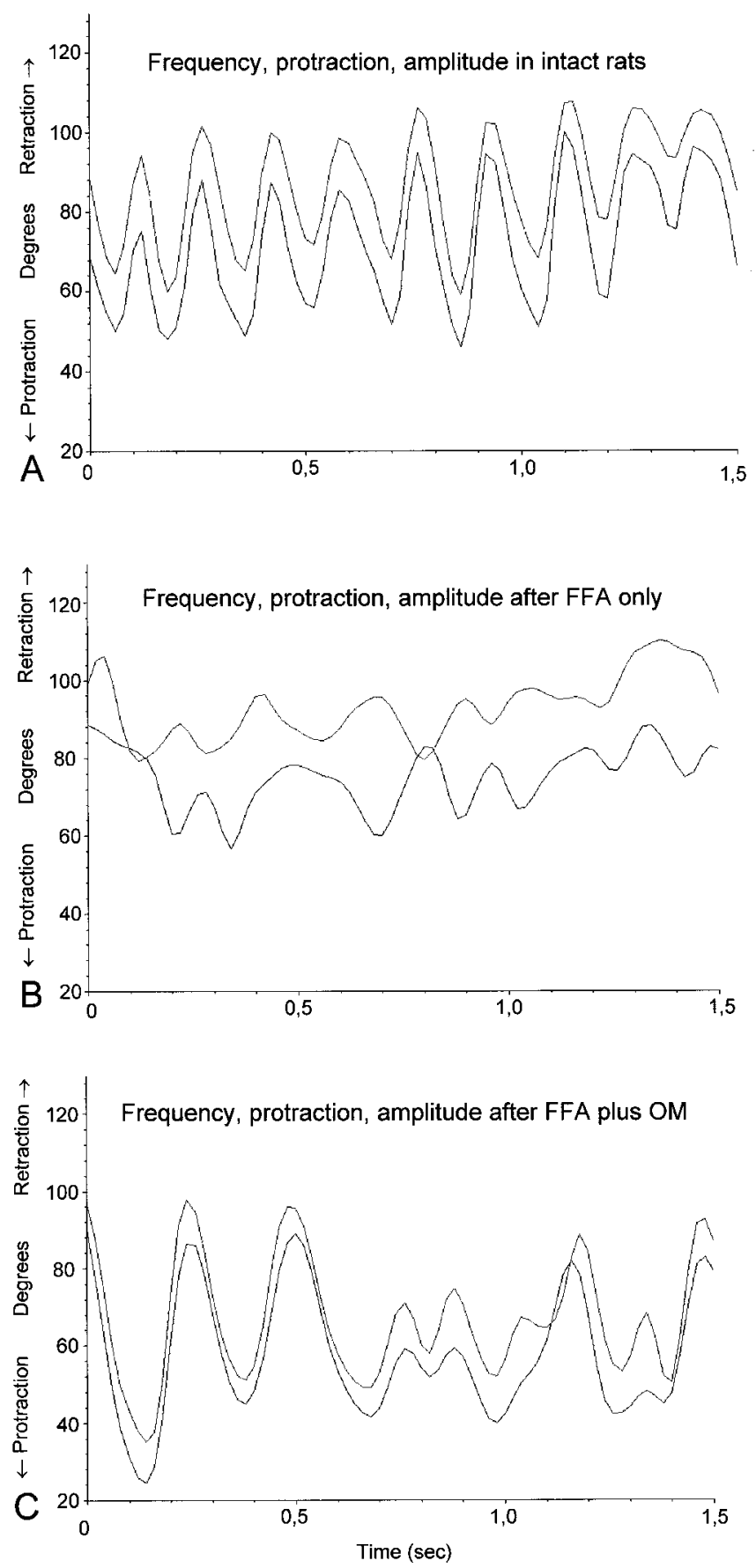

Figure 3. Biometric analysis of vibrissae motor performance. A, Graph of the changes in angles of two, large, C-row vibrissae during explorative cyclic whisking in intact rats. The parallel course of both curves indicates the synchronous movements of the two vibrissae. In this case, the frequency was $6 \mathrm{~Hz}$, the protraction was $\sim 55^{\circ}$, the retraction was $\sim 105^{\circ}$, and the amplitude was $\sim 50^{\circ}$. $B$, Faint and desynchronized whisker movements (protraction and retraction with very small amplitude) during an active exploration of a representative animal 2 months after FFA-only. $C$, Synchronous movement of two large vibrissae with a frequency of $5 \mathrm{~Hz}$, a protraction of $\sim 50^{\circ}$, and an amplitude of $\sim 40^{\circ}$ in a representative animal 2 months after FFA.

\section{Identification of the transplanted olfactory mucosa at the injury site using congenic markers}

Hybridization of sections from the transplantation site with a Y chromosome-specific DNA probe labeled a number of cell nuclei directly adjacent to the sutured facial nerve, indicating that the localization of the implant had not changed during the postoperative period. The reaction product was confined exclusively to portions of the cell nucleus. The nuclei of the host fibroblasts and Schwann cells remained blank (Fig. 4). Sometimes fragments of cross-sectioned conchae could be found. Our results, therefore, confirm previous reports on successful transplantation of olfactory epithelium to the anterior chamber of the eye (Barber et al., 1982) and to the brain (Holbrook et al., 2001).

\section{Transplanted olfactory mucosa induce a sustained expression of trophic factors at the lesion site}

It is well known that with the exception of CNTF, a number of trophic factors (e.g., NGF, BDNF, bFGF, IGF-I, and GDNF) are expressed by the denervated Schwann cells after buccal facial branch transection. In general, the immunoreactivity is detected at $1 \mathrm{~d}$ post-axotomy (DPA), reaches a maximum at 5-6 DPA, and after a gradual decline is no longer evident at 21-28 DPA (Heumann et al., 1987; Meyer et al., 1992; Funakoshi et al., 1993).

This is confirmed by the results of the present study, demonstrating no expression of CNTF, IGF-I, and GDNF and only a faint expression of BDNF and bFGF at the suture site 2 months after FFA (Fig. $5 A, B$ ) or FFA + BMM (Fig. 5C,D).

Contrary to this, an intense immunostaining for BDNF (Fig. $5 E$ ) and bFGF (Fig. 5F) was expressed in OM-transplanted animals. The higher magnification indicated immunoreactivity mostly in the Schwann cells, which were identified by their long and slender cell processes running parallel to the long axis of the nerve (Fig. 5G,H). A parallel immunostaining for S-100 protein, considered as a general marker of Schwann cells, showed that most of the cells that expressed NGF were Schwann cells (data not shown).

This may indicate that the transplanted OM directly or indirectly maintained the expression of trophic factors that otherwise would have been downregulated. Although these observations are in line with some earlier results (Buckland and Cunningham, 1999; Boruch et al., 2001), we cannot confine the immunoreactivity exclusively to Schwann cells, OECs, or basal cells of the olfactory epithelium.

\section{DISCUSSION}

The major finding of the present study is that transplantation of olfactory mucosa to the transected facial nerve reduces axonal branching and improves vibrissal motor performance. Implying a direct link between diminished axonal branching and recovery of motor function, our results also show that reinnervation of muscle targets by "foreign" motoneurons can yield good functional parameters, thus revealing the vast possibilities of neuronal plasticity.

\section{Neurobiological importance of post-transectional axonal branching}

When an axon is severed, the proximal cut end rapidly closes with a membrane seal (Fishman et al., 1990; Spira et al., 1993) and soon afterward forms a terminal swelling or "end-bulb" (Friede and Bischhausen, 1980; Fried et al., 1991). Within the following 3 $\mathrm{hr}$, numerous axonal branches begin to emerge from the end-bulb and start to elongate (Bisby and Pollock, 1983) at a rate of 1-4 mm/d (Tetzlaff and Bisby, 1989; Fawcett and Keynes, 1990). Under ideal conditions, only one of these branches actually reaches its original target. The navigation of these immature axons is under the control of short-range acting guidance cues, most of them deriving from the distal nerve stump. Thus, postlesional axonal branching is considered to represent the search of 

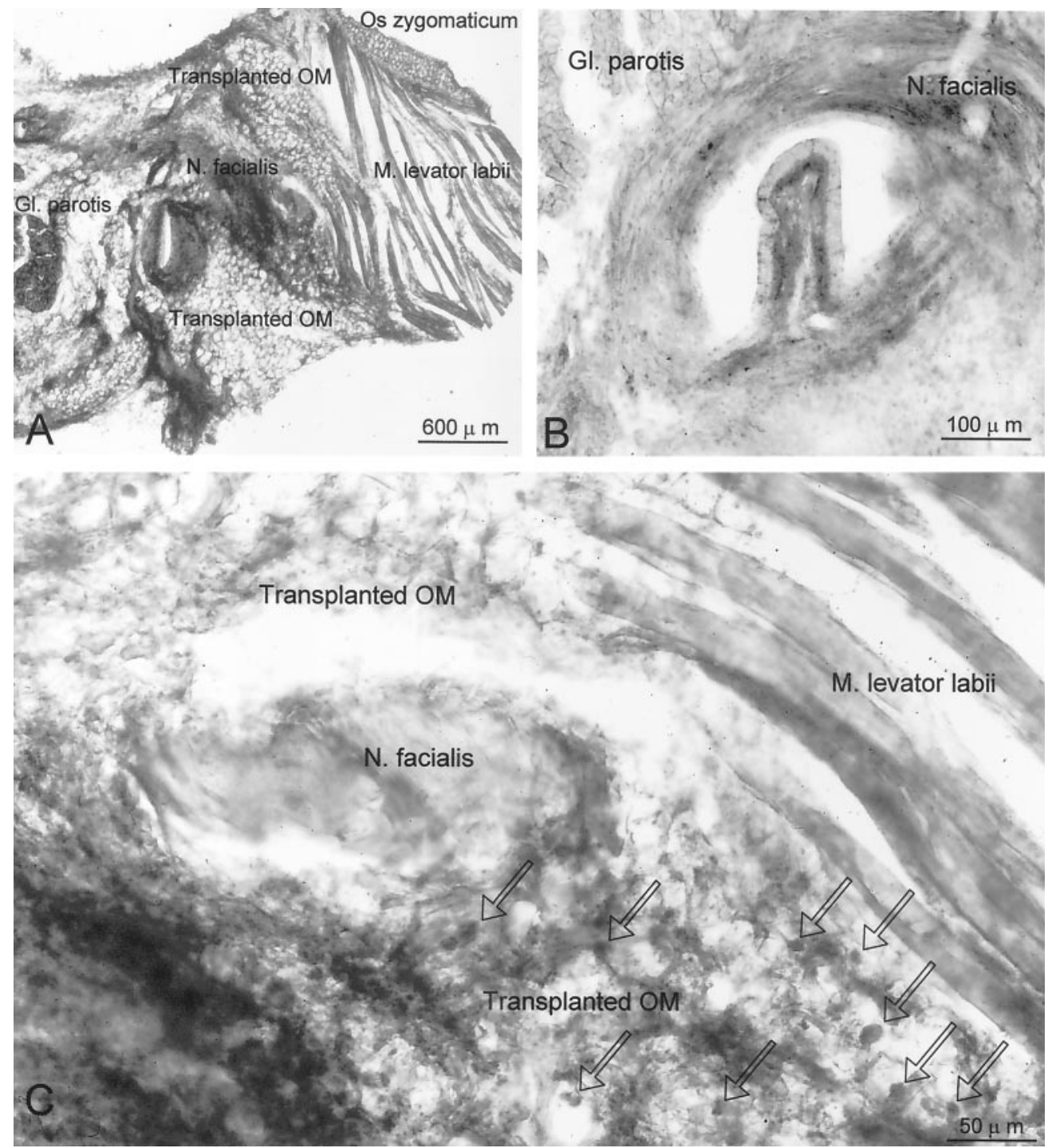

Figure 4. Detection of transplanted olfactory mucosa by in situ hybridization of a Y chromosome-specific cDNA probe on $40-\mu \mathrm{m}$-thick longitudinal sections. $A$, Overview of a section through the facial nerve and transplanted olfactory mucosa. $B$, In some cases, portions of preserved nasal conchae, derived from a male donor, could be observed adjacent to the parotid gland and the facial nerve. $C$, High-power magnification of a portion from $A$ showing numerous donor-derived positive nuclei (arrows) incorporated into the tissue close to the facial nerve. No nuclear staining is present in the fibers of the host levator labii muscle.

axons for local guidance cues necessary for their navigation (AlMajed et al., 2000). In general, however, these "actively searching" axons not only choose the wrong way, but also branch and project simultaneously along several different fascicles (subdivisions, rami) of a transected nerve trunk (Angelov et al., 1999). Thus, the process of branching, originally aimed at both neuronal and target survival, turns out to be responsible for the failure of axons to reinnervate solely their original domain (Fu and Gordon, 1997).

\section{The combined approach to evaluate the quality of peripheral nerve regeneration}

Recently we established simultaneous multiple neuronal labeling to study axonal branching (Angelov et al., 1999). In several earlier experimental sets, we conceptually divided the process of axonal regrowth into "axonal elongation" and "axonal branching." We hypothesized that an axonal elongation, which had been fostered by local application of extracellular matrix proteins or OECs, might reduce axonal branching and thus improve recovery of function. The subsequent neuron counts showed that despite their known effect to support neurite elongation, these procedures failed to suppress axonal branching in the facial nerve plexus (Dohm et al., 2000; Guntinas-Lichius et al., 2001).
Preoperative and postoperative neuronal labeling as a tool to study the accuracy of target reinnervation

Quantitative estimation after single tracing with HRP provides information solely on the reinnervation status of a muscle target, because the one-tracer approach cannot elucidate the relationship between preoperative and postoperative innervation of target muscles (Angelov et al., 1996; Streppel et al., 1998; GuntinasLichius et al., 2000). The sequential application of double retrograde labeling should allow an optimal evaluation of preoperative and postoperative distribution of motoneurons in the same animal, avoiding counting errors caused by inter-individual variability. Our experience shows that the best combination of fluorescent retrograde tracers to study the accuracy of post-transectional muscle reinnervation is a preoperative labeling of the original motoneuronal pool by an injection of $1 \% \mathrm{FG}$ into the muscle target, followed by a post-operative labeling of all motoneurons innervating the same target after surgery by an injection of $1 \%$ FB (Popratiloff et al., 2001).

The biometrics of whisking behavior provides a very sensitive analysis that we recently introduced as a tool to study facial nerve regeneration (Guntinas-Lichius et al., 2001). Under normal physiological conditions, the mystacial vibrissae of the rat are erect 

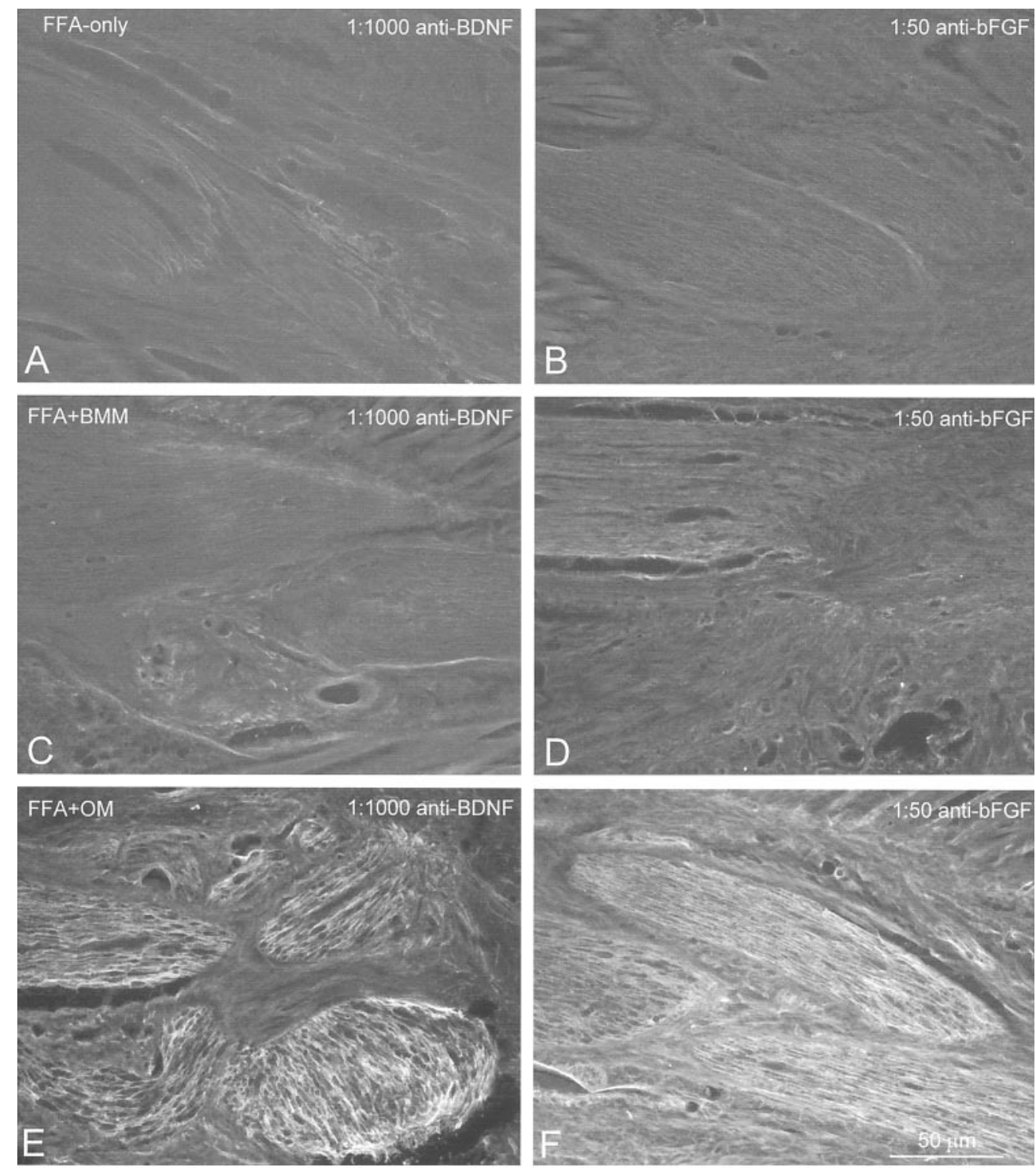

Figure 5. Expression of trophic factors at the suture/implantation site 2 months after FFA-only, FFA + BMM, or FFA + OM. Longitudinal sections through the facial nerve show a very faint $\operatorname{BDNF}(A, C)$ and $\mathrm{bFGF}(B, D)$ immunofluorescence after FFA-only and FFA + BMM, respectively. By contrast, 2 months after FFA + OM, the immunofluorescence for $\operatorname{BDNF}(E, G$, $H)$ and bFGF $(F)$ is intensive.
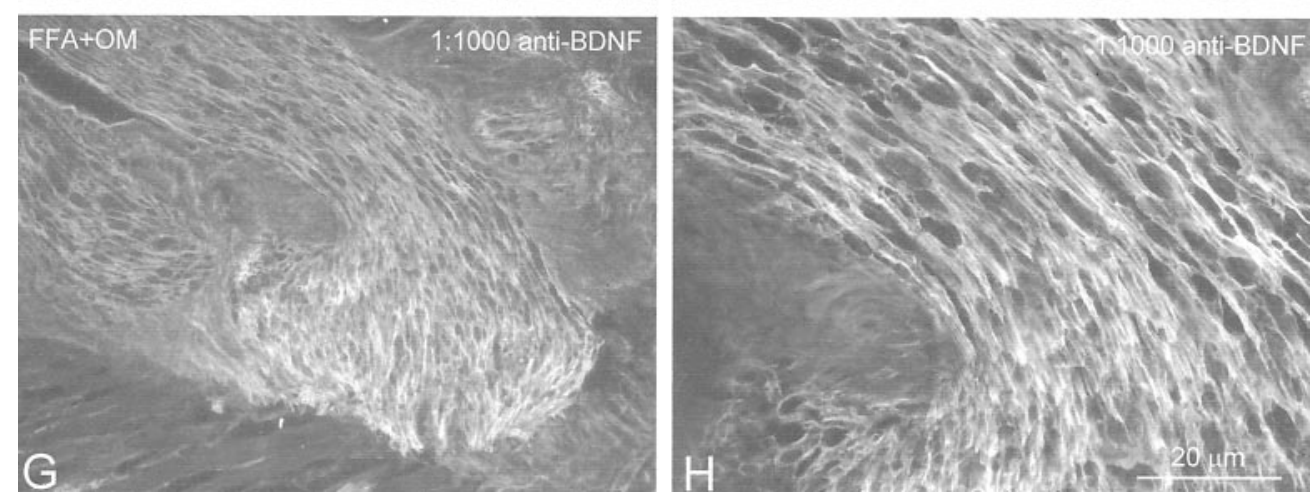

with anterior orientation. Their simultaneous sweeps known as "whisking" or "sniffing" (Welker, 1964; Semba et al., 1980) occur 5-11 times per second (Komisaruk, 1970; Carvell and Simons, 1990; Bermejo et al., 1996). The striated muscle fibers mediating protraction form a sling around the rostral aspect of each hair follicle; contraction of these muscles via branches of the facial nerve pulls the base of the follicle caudally, moving the distal aspects of the whisker hair forward. By contrast, retraction of the vibrissae depends primarily on passive elastic properties of deep connective tissue (Dörfl, 1985; Wineski, 1985).

\section{The nature of the beneficial effect of OM transplantation: moderate but long-lasting secretion of trophic molecules at the lesion site}

In this paper, we show that transplanted olfactory mucosa improves peripheral nerve regeneration after facial nerve injury. 
This effect as measured by functional and morphological analysis appears to be based mainly on the reduction of axonal collateral formation. Whether the observed effect was caused directly by the olfactory ensheathing glia present in the lamina propria or by other cells of the transplanted olfactory tissue cannot be determined by the present data. What can be said, however, is that the transplant was still in place at the lesion site at the end of the experiments, as shown by in situ hybridization using a $\mathrm{Y}$ chromosome-specific DNA probe. The second important point is whether the transplant itself directly exerted the regenerationpromoting effects or whether it may have stimulated beneficial secondary processes. Again, the presented data cannot answer this question unequivocally, mainly because only the outcome of the transplantation was monitored. Immunostaining for trophic factors demonstrated that the lesion site of OM-transplanted animals but not of the operated controls (FFA) was characterized by an increased expression of NGF, BDNF, and FGF-2. Thus, it is conceivable that the transplant prevented the downregulation of trophic factors and that the trophic factors may be responsible for the observed reduction in collateral sprouting and the good functional recovery. It remains to be demonstrated to what extent the OECs of the transplant contributed to the trophic factor expression.

OECs have been shown to promote axon regeneration and remyelination in various model systems (Li et al., 1997, 1998; Ramon-Cuéto et al., 1998). It was found that OECs, contrary to Schwann cells, reduced sprouting of central neurons and stimulated the growth into the distal part of the experimentally transected spinal cord. Contrary to this, transplantation of pure cultures of neonatal OECs to the transected facial nerve, using the same model system as in the present study, resulted in a dramatic increase in axonal sprouting (Guntinas-Lichius et al., 2001).

How is the apparent discrepancy with the present data explained? In our previous study, we used cultured cells of the neonatal rat instead of adult olfactory tissue, which was used in the present study. The expression profile both between neonatal and adult tissue and between cultured cells and intact tissue may account for the differing effects. Recent evidence implies that trophic factors and their receptors become upregulated on dissociation and cultivation of OECs. The expression of the CNTF receptor $\alpha$ subunit, for example, cannot be found in the developing olfactory bulb (Lee et al., 1997) but displays a robust expression in cultured OECs (Wewetzer et al., 2001). The differences in collateral sprouting after transplantation of cultured OECs and olfactory tissue therefore may reflect differing levels of trophic factors. This in turn would suggest that the amount of trophic factor is the critical factor that determines the degree of sprouting at the lesion site. This speculation is underscored by recent findings demonstrating that application of antibodies against trophic factors reduces collateral sprouting in the same model (Streppel et al., 2002).

The application of olfactory tissue that very likely contained fewer OECs than the implants may have induced more moderate effects. Because expression of trophic factors was noted in structures outside the implant itself, it is likely that the transplant induced and maintained trophic factor expression outside the implant.

After axotomy, trophic factors are taken up by regenerating axons to keep the neurons trophically satisfied (Di Stefano et al., 1992; Unsicker et al., 1992; Yan et al., 1992; Friedman et al., 1995; Sendtner et al., 1997). Accordingly, the synthesis of receptors for
NGF, BDNF, bFGF, GDNF, CNTF, and IGF-I is upregulated at the lesion site after axotomy (Meyer et al., 1992; Raivich and Kreutzberg, 1993; McMahon and Priestley, 1995; MacLennan et al., 1999). Apart from this "central effect" on neuronal cell bodies (promoting survival), numerous studies report on other "peripheral effects" of the trophic factors. For example, neurotrophins and bFGF have been shown to stimulate and hypermodulate neurite outgrowth, enlarge axon caliber, and induce sprouting of neurons in vitro and in vivo (Aebischer et al., 1989; Unsicker et al., 1993; Laquerriere et al., 1994; Fujumoto et al., 1997; Gallo and Letourneau, 1998; Batchelor et al., 2000; Davies, 2000; Deng et al., 2000; Mamounas et al., 2000).

Thus, we share the opinion that this unnecessarily forced axonal branching was most likely caused by excessive amounts of trophic molecules provided by the cultured OECs. In contrast, our present results show that the transplanted olfactory mucosa may provide a weaker but long-lasting secretion of neurotrophins and bFGF at the lesion site (quantitative evaluations are under way).

In conclusion, we showed that transplanted autologous olfactory mucosa to the sutured perineurium of a peripheral motor nerve significantly improved the quality of target innervation. The reduced axonal branching promoted a better axonal pathfinding, which in turn provided an excellent recovery of function.

\section{REFERENCES}

Aebischer P, Salessiotis AN, Winn SR (1989) Basic fibroblast growth factor released from synthetic guidance channels facilitates peripheral nerve regeneration across long nerve gaps. J Neurosci Res 23:282-289.

Aldskogius H, Thomander L (1986) Selective reinnervation of somatotopically appropriate muscles after facial nerve transection and regeneration in the neonatal rat. Brain Res 375:126-134.

AlMajed AA, Neumann CM, Brushart TM, Gordon T (2000) Brief electrical stimulation promotes the speed and accuracy of motor axonal regeneration. J Neurosci 20:2602-2608.

An J, Beauchemin N, Albanese J, Abney TO, Sullivan AK (1997) Use of rat cDNA probe specific for the $\mathrm{Y}$ chromosome to detect male-derived cells. J Andrology 18:289-293.

Angelov DN, Gunkel A, Stennert E, Neiss WF (1993) Recovery of original nerve supply after hypoglossal-facial anastomosis causes permanent motor hyperinnervation of the whisker-pad muscles in the rat. J Comp Neurol 338:214-224.

Angelov DN, Neiss WF, Streppel M, Andermahr J, Mader K, Stennert E (1996) Nimodipine accelerates axonal sprouting after surgical repair of rat facial nerve. J Neurosci 16:1041-1048.

Angelov DN, Skouras E, Guntinas-Lichius O, Streppel M, Popratiloff M, Walther M, Klein J, Stennert E, Neiss WF (1999) Contralateral trigeminal nerve lesion reduces polyneural muscle innervation after facial nerve repair in rats. Eur J Neurosci 11:1369-1378.

Anonsen CK, Trachy RE, Hibbert J, Cummings CW (1986) Assessment of facial reinnervation by use of chronic electromyographic monitoring. Otolaryngol Head Neck Surg 94:32-36.

Baker RS, Stava MW, Nelson KR, May PJ, Huffman MD, Porter JD (1994) Aberrant reinnervation of facial musculature in a subhuman primate: a correlative analysis of eyelid kinematics, muscle synkinesis, and motoneuron localization. Neurology 44:2165-2173.

Barber PC, Jensen S, Zimmer J (1982) Differentiation of neurons containing olfactory marker protein in adult rat olfactory epithelium transplanted to the anterior chamber of the eye. Neuroscience 7:2687-2695.

Batchelor PE, Liberatore GT, Porritt MJ, Donnan GA, Howells DW (2000) Inhibition of brain-derived neurotrophic factor and glial cell line-derived neurotrophic factor expression reduces dopaminergic sprouting in the injured striatum. Eur J Neurosci 12:3462-3468.

Bermejo R, Harvey M, Gao P, Zeigler HP (1996) Conditioned whisking in the rat. Somatosens Mot Res 13:225-233.

Bisby MA, Pollock B (1983) Increased regeneration rate in peripheral nerve axons following double lesions: enhancement of the conditioning lesion phenomenon. J Neurobiol 14:467-472.

Boruch AV, Conners JJ, Pipitone M, Deadwyler G, Storer PD, Devries GH, Jones KJ (2001) Neurotrophic and migratory properties of an olfactory ensheathing cell line. Glia 33:225-229.

Brown MC, Holland RL, Hopkins WG, Keynes RJ (1981) An assessment of the spread of the signal for terminal sprouting within and between muscles. Brain Res 210:145-151.

Brushart TM, Seiler WA (1987) Selective reinnervation of distal motor stumps by peripheral motor axons. Exp Neurol 97:289-300. 
Buckland ME, Cunningham AM (1999) Alterations of the neurotrophic factors glial cell line-derived neurotrophic factor, ciliary neurotrophic factor and brain-derived neurotrophic factor, in the target-deprived olfactory epithelium. Neuroscience 90:333-347.

Bunge RP (1993) Expanding roles for the Schwann cell: ensheathment, myelination, trophism and regeneration. Curr Opin Neurobiol 3:805-809.

Carvell GE, Simons DJ (1990) Biometric analysis of vibrissal tactile discrimination in the rat. J Neurosci 10:2638-2648.

Davies AM (2000) Neurotrophins: neurotrophic modulation of neurite growth. Curr Biol 10:198-200.

Di Stefano PS, Friedman B, Radziejewski C, Alexander C, Boland P, Schick CM, Lindsay RM, Wiegand SJ (1992) The neurotrophins BDNF, NT-3 and NGF display distinct patterns of retrograde axonal transport in peripheral and central neurons. Neuron 8:983-993.

Deng YS, Zhong JH, Zhou XF (2000) Effects of endogenous neurotrophins on sympathetic sprouting in the dorsal root ganglia and allodynia following spinal nerve injury. Exp Neurol 164:344-350.

Dörfl J (1985) The innervation of the mystacian region of the white mouse. A topographical study. J Anat 142:173-184.

Dohm S, Streppel M, Guntinas-Lichius O, Pesheva P, Probstmeier R, Walther M, Neiss WF, Stennert E, Angelov DN (2000) Local application of extracellular matrix proteins fail top reduce the number of axonal branches after varying reconstructive surgery on rat facial nerve. Restor Neurol Neurosci 16:117-126.

Esslen E (1960) Electromyographic findings on two types of misdirection of regenerating axons. EEG Clin Neurophysiol 12:738-741.

Evans PJ, Bain JR, Mackinnon SE, Makino AP, Hunter DA (1991) Selective reinnervation: a comparison of recovery following microsuture and conduit nerve repair. Brain Res 559:315-321.

Fawcett JW, Keynes RJ (1990) Peripheral nerve regeneration. Annu Rev Neurosci 13:43-60.

Fishman HM, Tewari KP, Stein PG (1990) Injury induced vesiculation and membrane redistribution in squid giant axon. Biochim Biophys Acta 1023:421-435.

Fried K, Govrin-Lippmann R, Rosenthal F, Ellisman M, Devor M (1991) Ultrastructure of afferent axon endings in a neuroma. J Neurocytol 20:682-701.

Friede RL, Bischhausen R (1980) The fine structure of stumps of transected nerve fibers in subserial sections. J Neurol Sci 44:181-203.

Friedman B, Kleinfeld D, Ip NY, Verge VMK, Moulton R, Boland P, Zlotchenko E, Lindsay RM, Liu L (1995) BDNF and NT-4/5 exert neurotrophic influences on injured adult spinal motor neurons. J Neurosci 15:1044-1056

Fu SY, Gordon T (1997) The cellular and molecular basis of peripheral nerve regeneration. Mol Neurobiol 14:67-116.

Fujumoto E, Mizoguchi A, Hanada K, Yajima M, Ide C (1997) Basic fibroblast growth factor promotes extension of regenerating axons of peripheral nerve. In vivo experiments using a Schwann cell basal lamina tube model. J Neurocytol 26:511-528.

Funakoshi H, Frisen J, Barbany G, Timmusk T, Zachrisson O, Verge VMK, Persson H (1993) Differential expression of mRNAs for neurotrophins and their receptors after axotomy of the sciatic nerve. J Cell Biol 123:455-465.

Gallo G, Letourneau PC (1998) Localized sources of neurotrophins initiate axon collateral sprouting. J Neurosci 18:5403-5414.

Gundersen HJ (1986) Stereology of arbitrary particles. A review of unbiased number and size estimators and the presentation of some new ones, in memory of William R. Thompson. J Microsc 143:3-45

Guntinas-Lichius O, Mockenhaupt J, Stennert E, Neiss WF (1993) Simplified nerve cell counting in the rat brainstem with the physical dissector using a drawing-microscope. J Microsc 172:177-180.

Guntinas-Lichius O, Angelov DN, Streppel M, Stennert E, Neiss WF (2000) Contributing factors to a better functional recovery after inevitable delayed nerve repair: enhanced regeneration through the predegenerated distal nerve stump. Exp Neurol 162:89-111.

Guntinas-Lichius O, Angelov DN, Tomov TL, Bramiga J, Neiss WF, Wewetzer K (2001) Transplantation of olfactory ensheathing cells stimulates the collateral sprouting from axotomized adult rat facial motoneurons. Exp Neurol 172:70-80.

Haas CA, Hofmann H-D, Kirsch M (1999) Expression of CNTF/LIFreceptor components and activation of STAT3 signalling in axotomized facial motoneurons: evidence for a sequential postlesional function of the cytokines. J Neurobiol, 41:559-571.

Hennig R, Dietrichs E (1994) Transient reinnervation of antagonistic muscles by the same motoneuron. Exp Neurol 130:331-336.

Heumann R, Korsching S, Bandtlow C, Thoenen H (1987) Changes of nerve growth factor synthesis in non-neuronal cells in response to sciatic nerve transection. J Cell Biol 104:1623-1631.

Holbrook EH, DiNardo LJ, Costanzo RM (2001) Olfactory epithelium grafts in the cerebral cortex: an immunohistochemical analysis. Laryngoscope 111:1964-1969.

Irintchev A, Langer M, Zweyer M, Theisen R, Wernig A (1997) Functional improvement of damaged adult mouse muscle by implantation of primary myoblasts. J Physiol (Lond) 500:775-785.

Ito M, Kudo M (1994) Reinnervation by axon collaterals from single facial motoneurons to multiple targets following axotomy in the adult guinea pig. Acta Anat 151:124-130.

Kimura J, Rodnitzky RL, Okawara SH (1975) Electrophysiologic analysis of aberrant regeneration after facial nerve paralysis. Neurology 25:989-993

Komisaruk BR (1970) Synchrony between limbic system theta activity and rhythmical behaviour in rats. J Comp Physiol Psychol 70:482-492.

Laquerriere A, Peulve P, Jin O, Tiollier J Tardy M, Vaudry H, Hemet J, Tadie M (1994) Effects of basic fibroblast factor and alpha melanocytic stimulating hormone on nerve regeneration through a collagen channel. Microsurgery 15:203-210.

Lee MY, Hofmann HD, Kirsch M (1997) Expression of ciliary neurotrophic factor receptor-a messenger RNA in neonatal and adult rat brain: an in situ hybridization study. Neuroscience 77:233-246.

Li Y, Field PM, Raisman G (1997) Repair of adult rat corticospinal tract by transplants of olfactory ensheathing cells. Science 277:2000-2002.

Li Y, Field PM, Raisman G (1998) Regeneration of adult corticospinal axons induced by transplanted olfactory ensheathing cells. J Neurosci $18: 10514-10524$

Lu J, Feron F, Ho SM, Mackay-Sim A, Waite PM (2001) Transplantation of nasal olfactory tissue promotes partial recovery in paraplegic adult rats. Brain Res 889:344-357.

Lu J, Feron F, Mackay-Sim A, Waite PM (2002) Olfactory ensheathing cells promote locomotor recovery after delayed transplantation into the transected spinal cord. Brain 125:14-21.

Mackay-Sim A, Chuah MI (2000) Neurotrophic factors in the primary olfactory pathway. Prog Neurobiol 62:527-559.

Mackinnon SE, Dellon AL, Lundborg G, Hudson AR, Hunter DA (1986) A study of neurotrophism in a primate model. J Hand Surg 11:888-894

Mackinnon SE, Dellon AL, Obrien JP (1991) Changes in nerve fiber diameters distal to a nerve repair in the rat sciatic nerve model. Muscle Nerve 14:1116-1122.

MacLennan AJ, Devlin BK, Neitzel KL, McLaurin DL, Anderson KJ, Lee N (1999) Regulation of ciliary neurotrophic factor receptor $\alpha$ in sciatic motor neurons following axotomy. Neuroscience 91:1401-1413.

Madison RD, Archibald SJ, Lacin R, Krarup C (1999) Factors contributing to preferential motor reinnervation in the primate peripheral nervous system. J Neurosci 19:11007-11016.

McMahon SB, Priestley JV (1995) Peripheral neuropathies and neurotrophic factors: animal models and clinical perspectives. Curr Opin Neurobiol 5:616-624

Mamounas LA, Altar CA, Blue ME, Kaplan DR, Tessarollo L, Lyons WE (2000) BDNF promotes the regenerative sprouting, but not survival, of injured serotonergic axons in the adult brain. J Neurosci 15:771-782.

Meyer M, Matsuoka I, Wetmore C, Olson L, Thoenen H (1992) Enhanced synthesis of brain-derived neurotrophic factor in the lesioned peripheral nerve: different mechanisms are responsible for the regulation of BDNF and NGF messenger RNA. J Cell Biol 119:45-54.

Montserrat L, Benito M (1988) Facial synkinesis and aberrant regeneration of facial nerve. Adv Neurol 49:211-224.

Morris J, Hudson AR, Weddell G (1972) Study of degeneration and regeneration in the divided rat sciatic nerve based on electron microscopy. II. The development of the "regenerating unit." Z Zellforsch Mikrosk Anat 124:103-130.

O'Leary MT, Blakemore WF (1997) Oligodendrocyte precursors survive poorly and do not migrate following transplantation into the normal adult central nervous system. J Neurosci Res 48:159-167.

Popratiloff A, Neiss WF, Skouras E, Streppel M, Guntinas-Lichius O, Angelov DN (2001) Evaluation of muscle reinnervation employing pre- and post-axotomy injections of fluorescent retrograde tracers. Brain Res Bull 54:115-123.

Raisman J (2001) Olfactory ensheathing cells: another miracle cure for spinal cord injury? Nat Rev Neurosci 2:369-373.

Raivich G, Kreutzberg GW (1993) Peripheral nerve regeneration: role of growth factors and their receptors. Int J Dev Neurosci 11:311-324.

Ramon-Cuéto A, Plant GW, Avila J, Bunge MB (1998) Long-distance axonal regeneration in the transected adult rat spinal cord is promoted by olfactory ensheathing glia transplants. J Neurosci 18:3803-3815.

Rich MM, Lichtman JW (1989) In vivo visualization of pre- and postsynaptic change during synapse elimination in reinnervated mouse muscle. J Neurosci 9:1781-1805.

Semba K, Szechtman H, Komisaruk BR (1980) Synchrony among rhythmical facial tremor, neocortical "alpha" waves, and thalamic nonsensory neuronal bursts in intact awake rats. Brain Res 195:281-298.

Sendtner M, Götz R, Holtmann B, Thoenen H (1997) Endogenous ciliary neurotrophic factor is a lesion factor for axotomized motoneurons in adult mice. J Neurosci 17:6999-7006.

Shawe GD (1954) On the number of branches formed by regenerating nerve fibers. Br J Surg 42:474-488.

Spira ME, Benbassat D, Dormann A (1993) Resealing of the proximal and distal cut ends of transected axons: electrophysiological and ultrastructural analysis. J Neurobiol 24:300-316.

Streppel M, Angelov DN, Guntinas-Lichius O, Hilgers RD, Rosenblatt 
JD, Stennert E, Neiss WF (1998) Slow axonal regrowth but extreme hyperinnervation of target muscle after suture of the facial nerve in aged rats. Neurobiol Aging 19:83-88.

Streppel M, Azzolin N, Dohm S, Guntinas-Lichius O, Haas C, Grothe C Wevers A, Neiss WF, Angelov DN (2002) Focal application of neutralizing antibodies to soluble neurotrophic factors reduces collateral axonal branching after peripheral nerve lesion. Eur J Neurosci $15: 1327-1342$

Tetzlaff W, Bisby MA (1989) Neurofilament elongation into regenerating facial nerve axons. Neuroscience 29:659-666.

Unsicker K, Grothe C, Westermann R, Wewetzer K (1992) Cytokines in neural regeneration. Curr Opin Neurobiol 2:671-678.

Unsicker K, Grothe C, Lüdecke G, Otto D, Westermann R (1993)
Fibroblast growth factors: their roles in the central and peripheral nervous system. In: Neurotrophic factors (Loughlin SE, Fallon JH, eds), pp 313-338. New York: Academic.

Welker WI (1964) Analysis of sniffing of the albino rat. Behaviour 22:223-244.

Wewetzer K, Grothe C, Claus P (2001) In vitro expression and regulation of ciliary neurotrophic factor and its $\alpha$ receptor unit in neonatal rat olfactory ensheathing cells. Neurosci Lett 306:165-168.

Wineski LE (1985) Facial morphology and vibrissal movement in the golden hamster. J Morphol 183:199-217.

Yan Q, Elliott JL, Snider WD (1992) Brain-derived neurotrophic factor rescues spinal motor neurons from axotomy-induced cell death. Nature 360:753-755. 